\title{
12
}

\section{NEW CONCEPTS IN URBAN WATER MANAGEMENT}

\author{
Janusz Niemczynowicz \\ Department of Water Resources Engineering, \\ University of Lund \\ Sweden
}

\begin{abstract}
Present water management must change in order to alleviate water- related environmental and health problems of growing population in the world. The target is to use novel technologies capable to recycle nutrients present in wastewater and organic part of solid waste to agricultural production. Key technologies that should be developed are: bioconversion methods, dry sanitation, separation sanitation, other locally adapted wast water treatment and recycling methods such as aquaculture systems, wastewater irrigation. New goals of sustainable development put new targets to be addressed in research and development activities conducted both on scientific and professional levels.
\end{abstract}

\section{INTRODUCTION}

Sustainability goals, formulated in a long row of international meetings on a governmental level have induced a still on-going discussion about the role of science in the process of change towards the new goals. In this process it became more and more obvious that water sciences and water management have a very important role to play. Methods of utilization and recycling large amounts of nutrients from wastewater from growing cities must be urgently developed. The target is to turn the problems to opportunities: to alleviate environmental problems with organic pollution of rivers and coastal waters and, simultaneously, to improve health and living conditions in urban areas and to make huge amounts of nutrients present in wastewater available for boosting agricultural production urgently needed for the growing population. In the water profession, the understanding of the realities of the present world should bring a rapid change in education, research and in technological praxis. 


\section{MISSING TREATMENT}

The stark facts of the matter are that, of all the wastewater in the world, $95 \%$ of it is released to the environment without treatment. What is more, three billion people lack sanitation and, if sanitation provision continues on its present course, up to 5.5 billion people will be without sanitation by the year 2035, many of whom will be living in crowded urban settlements. As a consequence of these sanitation deficiencies, 3.3 million people die annually from diarrhoeal diseases, with 3.5 billion infected. In Africa alone, 80 million are at risk from cholera and the 16 million cases of typhoid infections each year are a result of lack of adequate sanitation and clean drinking water (WMO 1996a). The main reason for this situation is the high cost of water-borne sanitation. The investment needed to provide such systems is far beyond the means of the respective countries and international organizations. In many countries, even if the necessary sanitation water and infrastructure and treatment plants were constructed free of charge, the country would not be able to maintain them. According to Grau (1994), countries with annual per capita GNP below US $\$ 1000$ not only lack the resources to construct treatment plants bur also cannot maintain them.

Full coverage with sanitation and treatment is achieved only in rich countries, serving only $6 \%$ of the world's population, and even then it is achieved at a cost of excessive use of natural resources. Conventional sewerage systems are not providing equal opportunities for all, and therefore they cannot contribute to equity between the rich and poor peoples and countries. Thus the high costs of western solutions have created conditions in which lack of safe water and decent sanitation creates an enormous global environmental impact, degrades the health of populations and endangers resource security.

\section{WATER CONSUMPTION NEEDS}

In parallel with rising urban populations, drinking water demand in urban areas, especially in megacities in developing countries, is growing and taking an increasing proportion of total water resources. In spite of the efforts during UNESCO's International Decade 1981-1990, about 1.2 billion people in developing countries still lack access to safe drinking water. Furthermore, all delivered water will be contaminated if water closets are used, so that all water expelled from our homes water use is called "wastewater" - a term which could more appropriately be replaced by "wasted water".

Decreasing availability of clean water in the world suggests that water-borne sanitation is not a reasonable solution for any country and certainly not for dry countries. Thus, next important connection can be made: one of main reasons for shortage of clean drinking water is a wrong assumption that water consumption must contain volumes necessary for water-bone sanitation. 


\section{VIEWS OF CENTRAL ORGANIZATIONS}

WHO's Collaborative Council Working Group on Sanitation (WHO 1996b) concluded that the progress of sanitation in the developing countries is hindered by basic misconceptions or myths stating that water is allways needed for good sanitation.

Regarding future sanitation systems, recommendations of the Habitat II state: "Governments at the appropriate levels in partnership with other actors should: ... Promote the development and use of efficient and safe sanitary systems such as dry toilets for the recycling of sewage and organic components of domestic waste into useful products such as fertilizers and bio-gas" (Habitat Agenda, Chapter IV, item $141 \mathrm{j}, 1996$ ). This statement can be considered as major progress in an attempt to connect several issues that have never been connected before.

World Health Organization's Collaborative Council Working Group on Water and Sanitation says: "Aid agencies are encouraged to support research into sanitation systems without water", and: "Educational and training institutions need to adjust their curricula away from sewerage and other water-related sanitation systems and focus on the realities of the world with scarce water resources, growing populations and increasing urbanization" (WHO 1996b). These statements prove that the WHO Working Group has, during several meetings in more than three years of discussions and investigations, come to the right conclusion that future sanitation systems for the growing world population cannot be based on water.

\section{STATUS SYMBOL}

The current praxis in the water and sanitation profession is a result of historical development that took place at the beginning of this century in the temperate climate of Northern Europe and North America. This praxis has served well during many decades in many countries in these regions and has brought important improvements in health conditions. This unquestioned success has resulted in a strong belief that such praxis and the assumptions behind it are also valid in other climatic conditions and in other times, when societal goals have changed. This extension of regional praxis to a generally and always valid "sanitation paradigm" is a mistake that has brought the present disastrous results. The incorrect assumption that water-borne sanitation is the only good solution for all peoples and countries has brought economic burdens, lack of any sanitation for almost half of the world's population, and global environmental pollution. This, in turn, has substantially contributed to present lack of equity among peoples and countries, and has put the possibility of sustainable development in danger.

There are a few examples of projects promoting implementation of inexpensive, simple and safe dry sanitation solutions. One such project has been completed in a rural area with about 6000 inhabitants north of Hanoi, Vietnam (Winblad 1996). Urine-separating and faeces-desiccating latrines were successfully introduced, bringing clear improvements in health. In spite of the success, it is not 
certain that the results of the project will last. The problem is that the water closet is Still a status symbol. This means that as wealth increases, water- borne sanitation will in turn be installed, missing the opportunity for low water use and the safe reuse of nutrients in agriculture. Status symbols come from the developed world, so it is only a new, modern, water-less closet that has found general use first in developed countries that can create a new status symbol. This is why research in water and sanitation and recognition of links to other sectors is so important.

\section{WHY NUTRIENT RECYCLING?}

World Bank predictions indicate that over the next 40 years production of food must increase by a factor of at least three, yet present statistics show that total grain production per capita is decreasing, with no signs of change. In order to reverse this trend, huge amounts of nutrients will be required to increase food production. This will require expansion of agriculture, which can be achieved with increasing use of fossil fertilizers and pesticides, potentially bringing economic burden, environmental pollution and a further decrease of clean water resources. The alternative is that nutrients present in wastewater (phosphorous, nitrogen, potassium and carbon) could be used in agriculture instead of fertilizers: the nutrient content of the excreta of one person is sufficient to produce grain containing all the nutrition necessary to maintain the life of one person. Thus, theoretically, there is no reason for hunger for anybody. So an important conclusion can be drown: an important reason for hunger in the world is the lack of sanitation technology capable of recycling nutrients from households to agriculture.

\section{POSITIVE SIGNS}

An exciting development is going on initiated not by the water profession but by dedicated individuals at a local communal level. Agenda 21 has been taken very seriously by communities in many European countries. In Sweden, for example, all communities are obliged by the Government to prepare and begin implementation of Agenda 21 action plans. Practitioners in the communities are proceeding with implementation of new system solutions for stormwater disposal and sanitation in new housing areas, in schools and in other public utility buildings. Local disposal and treatment of stormwater, source control and recycling of solid wastes and reuse of construction materials from demolished houses, substitution of water closets with composting or urine-separating toilets are examples of technologies used in this new type of actions. Sweden has set the goal of recycling at least $25 \%$ of all nutrients produced in sanitation systems to agriculture within next 10 years without increasing concentrations of conservative pollutants in soils. This requires dry or urine-separating solutions and changes, for example, in construction of houses and cities. 
Thus, it is not obvious that in the future clean water should be used for transportation of any contaminated material such as faeces from toilets and the organic part of household wastes. Water consumption can be reduced drastically if not used in sanitation facilities, and this requires development of new water system solutions.

As a target for the future, all organic material that is produced in a household should be recycled by employing micro-organisms to produce biogas and fertilizers. This can be realized in bio-reactors that optimize physical and chemical conditions for microbiological digestion (Gajdos 1995). This requires, in turn, use of other and better combinations of human residuals from households rather than present systems mixing clean water with polluted faeces. We should realize the potential of systems that don't mix useful and harmful elements in human residuals. Human urine itself constitutes valuable, practically bacteria-free readyto-use fertilizer. Human faeces and the organic part of solid wastes are infected but can be made sterile by microbial digestion and used for production of energy and fertilizers. In such win- win solution, instead of health problems and environmental pollution, human residuals can constitute a resource for boosting agricultural production, alleviating problems connected with storage of solid wastes, and delivering renewable energy. Key words in this context are "Bioconversion", "Dry sanitation", "Separation sanitation", "Aquaculture systems", "Wastewater reuse". Details of practical solutions using these technologies may look different depending of local climate, culture, traditions and available materials, but development of these technologies is one of the most important research topics to-day.

\section{RESEARCH TARGETS}

\section{Bioconversion}

Main objective of bioconversion technology is upgrading of renewable organic raw material to valuable products. Organic matter present in wastewater and organic part of waste constitutes a source of plant nutrients and renewable bioenergy and, thus it constitutes a raw material for bioconversion. Thus the process of bioconversion is a process that is able to convert organic material to biofertilizer and bioenergy. The end products produced in a bioconversion process should be clean of environmental pollution. Plant nutrients in biofertilizer should be also free of pathogens in order to be suitable for production of crops in agriculture, horticulture or forestry. For successful bioconversion of solid and liquid organic waste, it is necessary to collect the organic fraction of waste close to the source in order to obtain raw material which is not contaminated by heavy metals and chemicals harmful to microorganisms involved in processes of bioconversion. Thus, central sorting is not very suitable for a purpose of bioconversion.

The process of bioconversion may be conducted in different types of isolated containers called "bioreactors" in which physical and chemical conditions are carefully regulated so that the microbial processes are optimized. Thus, the notion "bio-reactor" means any facility able to achieve bioconversion of solid and liquid 
wastes. It may require relatively high level of technology i.e. monitoring chemical composition of raw materials, regulating physical and chemical conditions under the process and in the end products.

The set-ups that meet all requirements for proper bioconversion with clean end products exists only in small sale in laboratories (Lund University, Department of Biotechnology and Swedish Agricultural University, Alnarp). Larger scale experience in bioconversion is limited to experimental set-ups in which raw material consists of more or less mixed solid wastes. The end-products cannot meet the above stated requirements and only biogas can be used.

\section{Dry sanitation}

It is increasingly argued that sanitation systems should not mix clean water with bacteria contaminated material such as faeces. Usual motivation for such stand point is that such systems require central disposal and treatment. Though the complexity of such systems, new external pollution are added making re-use of nutrients difficult. As opposition to water sanitation, dry sanitation solutions are thus advocated for. As an argument for the use of dry solutions, increased potential for recycling unpolluted nutrients is usually stressed.

\section{Separation sanitation}

Substitution of water closets with urine separating toilets is advocated by increased number of people and especially by representatives of farmer associations. Farmers realize benefits of using urine instead of chemical fertilizers, possibly because products from such farming can be classified as ecological, and this results in a growing market for human urine. Human urine contains about $5.6 \mathrm{~kg}$ $\mathrm{N}, 0.5 \mathrm{~kg} \mathrm{P}$ and $1.0 \mathrm{~kg} \mathrm{~K} /$ person and year and thus it may represent a considerable value as a biofertilizer. Leaving human body, it is practically bacteria-free and, if preserved against contact with air and not contaminated during collection, storage and transport, it constitutes a ready-to-use fertilizer. It is argued that change from artificial fertilizers to the use of human urine may alleviate the present dependence on fossil fertilizers, decrease environmental pollution and payoff in a short time. However, the technology of separation is new, and not much experience exists about collection, transportation, safe storage and handling of human urine. Several questions regarding safe use of urine in agricultural production are not answered. Further un-restricted application of urine in agriculture may bring un-expected harmful effects both on quality of products and human health as well as on the environment. It is thus essential to conduct thorough research on separation technology, processing, storage and use of urine before adverse effect will occur. 


\section{Wastewater treatment using aquaculture}

In several countries multi-stage aquaculture systems have been used for centuries as a traditional method of recycling nutrients from domestic uses to agricultural and horticultural production. These systems involve similar processes as in natural ecosystem cycles, where the waste of one process becomes the raw material for another. One application example of such technology in Sweden is indoor wastewater treatment plant at Stensund that integrates sewage treatment, biomass cultivation (algae, higher plants and fish) and waste heat reclamation. In recent years however the notion "aquaculture" has been assigned to various single-step systems such as in-sea fish farming. There is no independent evaluation which of aquaculture systems, and on which level of complexity these systems could deliver a viable option to be wider applied for wastewater treatment in Northern Europe. The main problems of multi-level systems are their dependence on climatic conditions and vulnerability to toxic pollution. Thus, the applicability of such systems in different climate conditions should be investigated.

\section{CONCLUSIONS}

In times of rapidly increasing understanding of the crucial role of water-related planning and management in development of societies towards sustainability, the water profession should take a leading role and, instead of continuing business as usual, revise present practices and begin to contribute to the development of new sustainable system solutions that are capable to recycle nutrients from wastewater, reuse stormwater and, finally, recycle all organic components of domestic "wastes". At present, roughly $90 \%$ of research in water sector serve the needs of about $6 \%$ of world population. New curricula in educational and research institutions should be developed in order to change present professional praxis in water management according to Agenda 21 principles.

If we all change our views and act accordingly, the world will have a chance. If we fail to do this, global thirst, hunger, miscontent, national and international conflicts and wars will result in the near future. 


\section{REFERENCES}

Gajdos, R. (1995): "Composting in static bioreactors in laboratory. 1.Effects of Insulation on Temperature and PH". In: Recovery „Recycling, Re-integration", Vol.IV, published by EMPA, Dubendorf, Switzerland. Editors Anis Barrage \& Xaver Edelmann, pp. IV, 209-214.

Grau, P.(1994): "What next?". Water Quality International No.4, 1994, pp. 29-32.

WHO (1996a): World Health Organization: "Water Supply and Sanitation Sector Monitoring" Report 1996: "Sector Status as of 31 December 1994". WHO/EOS/96.15. Geneva, Switzerland.

WHO (1996b): "The Problem of Sanitation", Report of WHO Collaborative Council Working Group on Promotion of sanitation. Fifth Draft, Geneva, December 1996.

Winblad (1996): "Towards Ecological Approach to Sanitation". Proceedings of International Toilet Symp., Toyama, October 9, pp 5-6. 